\title{
Mejoramiento genético y producción de "semilla" de ajo (Allium sativum L.). Posibilidades de adaptación a diferentes ambientes
}

\author{
Garlic (Allium sativum L.) genetic improvement \\ and seed production. Possibilities of adaptation \\ to variable environments
}

Ajo 'CASTAÑo INTA'.

Foto: INTA, Argentina.

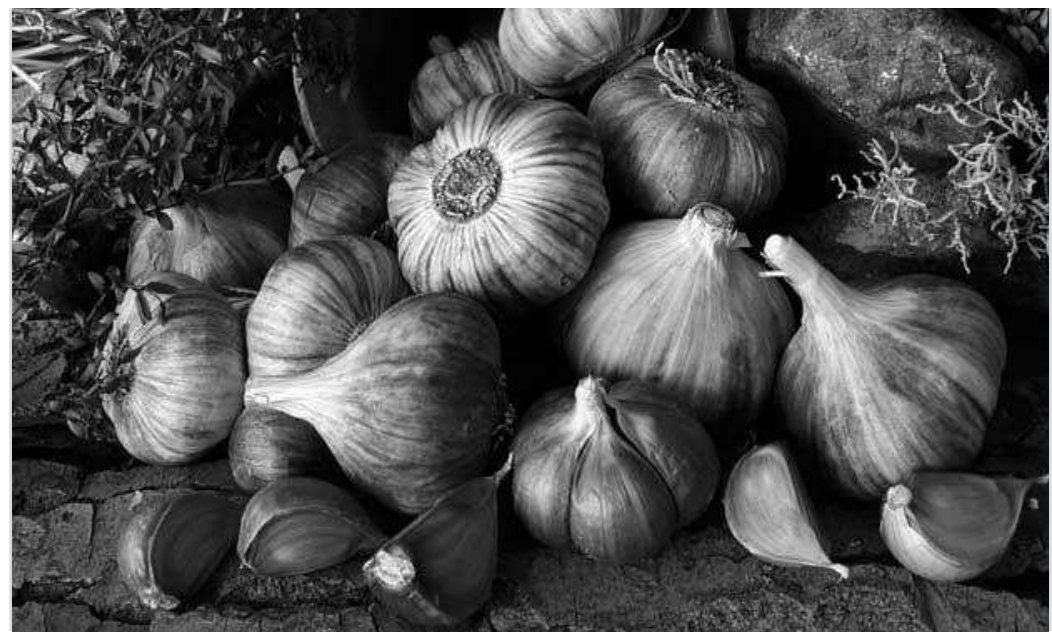

\section{RESUMEN}

Algunos ecotipos de ajo son capaces de florecer y producir semilla botánica, sin embargo la selección clonal sigue siendo la herramienta más válida para aprovechar la abundante variabilidad genética que tiene esta especie y sus variedades botánicas (var. sativum; var. ophioscorodon; var. pekinense). Estas variaciones y la fuerte interacción que tiene esta especie con el ambiente (por su reñida relación con el termo-fotoperiodo) hacen que en el mundo se confundan ecotipos, biotipos, tipos comerciales y cultivares. La selección clonal puede ser masal o individual. La masal es más efectiva desde el punto de vista de la cantidad de "semilla" alcanzada, pero más demorada para encontrar las mejores respuestas. La individual alcanza más rápido los objetivos propuestos, pero es más lenta para alcanzar grandes volúmenes de "semillas". En el transcurso de seis o siete años puede lograrse una nueva variedad de ajo, capaz de superar en ensayos comparativos a los testigos locales. Este nuevo material, luego de inscribirse formalmente en un registro, pasa a la etapa de producción de "semilla". Para formalizar un programa de producción de "semilla" de ajo debe contarse con legislación y normas específicas que protejan el patrimonio genético y sanitario de un país. Multiplicaciones seriadas año tras año generan diferentes categorías de "semillas fiscalizadas" (básicas, registradas, certificadas). En el mercado se conocen "semillas mejoradas", (provenientes de planes de selección), y "semillas saneadas", (provenientes de sistemas de control sanitario de virosis y otras patologías). Éstas pueden ser inicialmente multiplicadas in vitro y luego por multiplicación convencional, sin embargo existen alternativas intermedias que mejoran los tiempos de disponibilidad y el negocio, como son las multiplicaciones a través de bulbillos aéreos. Conocer a qué grupo ecofisiológico pertenecen las cultivares es imprescindible para predecir la adaptación y el comportamiento en diferentes ambientes.

1 Coordinador Nacional Proyecto Ajo/INTA, Mendoza, Argentina. jburba@laconsulta.inta.gov.ar 


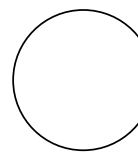

Palabras clave adicionales: selección clonal, ecotipos, tipos comerciales, cultivares, grupos ecofisiológicos, semilla certificada.

\section{ABSTRACT}

Some ecotypes of garlic (Allium sativum L.) are capable of blooming and producing botanical seeds, nevertheless the clonal selection remains to be the most valuable tool to make use of the abundant genetic diversity that have this species and its botanical varieties (var. sativum, var. ophioscorodon, var. pekinense). These changes and the strong interaction that this crop presents with the environment, such as the one related to thermoand photoperiod, makes that the ecotypos, biotypes, varieties and cultivars are worldwide mistaken. The clonal selection can be mass or individual. The mass selection is more effective from the point of view of the quantity of acquired "seed", but more delayed in terms of the best responses. The individual selection reaches more rapidly the proposed goals, but it is slower to reach large volumes of "seeds". In the course of six or seven years, it can be achieved a new variety of garlic, capable of overcoming in comparative essays the local control plants. After formal registration in a record, this new material enters the stage of "seed" production. In order to formalize a program of garlic "seed" production, one must be provided with legislation and specific norms that should protect the genetic and sanitary patrimony of the country. Serial multiplications year after year generate different categories of "fiscal seeds" (basic, registered, and certified). On the market these are known as "improved seeds" (proceeded from selection plans) and "healthy seeds" (proceeded from the systems of sanitary control of viruses and other pathogens). These can be initially multiplied in vitro and then via conventional multiplication, nevertheless there exist intermediate alternatives that improve the period of availability and commercialization, such as the multiplications through aerial bulbils. Knowing the ecophysiological group to which the culture belongs is essential to predict its adaptation and behaviour in different environments.

Additional key words: clonal selection, ecotypes, commercial types, cultivars, ecophysiological groups, seed quality certification.

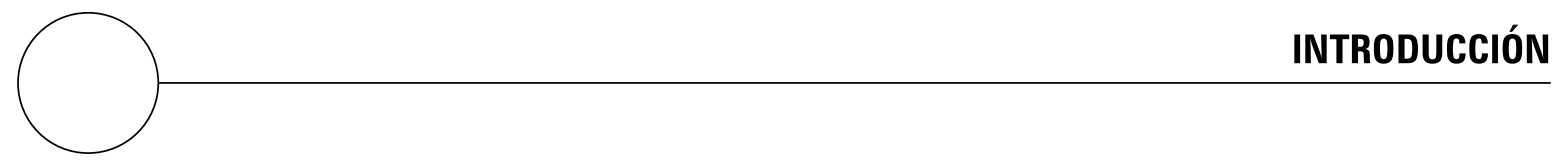

El mejoramiento genético del ajo (Allium sativum L.) ha sido motivo de encuentros y desencuentros e historias curiosas. Durante mucho tiempo de la edad moderna y contemporánea nadie creyó en la posibilidad de mejora genética del ajo bajo el argumento que una especie agámica estricta como el ajo no tenía fuentes de variabilidad.

Cuando en la década del cincuenta un investigador ruso anunció haber encontrado en un clon la capacidad de dar semilla botánica, otros tantos se encargaron de demostrarlo, ya que nadie lograba que sus plantas produjeran semillas siguiendo su técnica (Burba, 2008).
Tuvieron que pasar más de 30 años para que un investigador japonés encontrara "nuevamente" plantas con semilla que casualmente eran del mismo ecotipo ruso ya reportado. Aún hoy no existe en el mercado un cultivar comercial obtenido por hibridación, por lo que la técnica tradicional de selección clonal sigue siendo la principal herramienta.

La carencia de reproducción sexual en esta especie y, en consecuencia, la falta de recombinación meiótica limitan la variabilidad natural sólo a la acumulación de mutaciones somáticas, sin que puedan descartarse otras fuentes secundarias de 
variabilidad de menor frecuencia, como pueden ser las recombinaciones mitóticas o la presencia de tramposones (Lopez Frasca et al., 1997).

Miles de años de acumular pequeños pero significativos cambios (no muy perceptibles por parte del agricultor), acompañados de selección negativa (se venden los bulbos grandes y se guardan para semilla los bulbos chicos), contribuyeron para que el ajo en el mundo llegara a mediados del siglo pasado a su piso más bajo. La selección y la liberación de virus fueron las herramientas para superar esas barreras comerciales.

Hoy existen cultivares con muy bajas y muy altas concentraciones de allicina y de inulina; muy suaves y muy picantes; con y sin aptitud como saborizante de panes; con muy altas y muy bajas concentraciones de selenio; muy precoces y muy tardíos; con y sin fuentes de tolerancia a enfermedades causadas por hongos y virus; con pocas o muchas propiedades antiplaquetarias en sangre; aptos para el pelado, deshidratado o elaboración de fármacos.

Si bien en la actualidad algunos ecotipos de ajo son capaces de florecer y producir semilla botánica, la selección clonal sigue siendo la herramienta más válida para aprovechar la abundante variabilidad genética que tiene esta especie (Allium sativum) y sus variedades botánicas (var. sativum; var. ophioscorodon y var. pekinense).

Allium sativum var. sativum son los ecotipos más comunes de ajos "rosados", "violetas", "blancos" $y$ "colorados", mientras que $A$. sativum var pekinense corresponde a los ajos "morados", mal llamados "chinos". A. sativum var ophioscorodon son los ajos "castaños", mal llamados "rusos" o "polacos" (Burba, 2008).

La falta de selección sistemática durante siglos hizo que las actuales poblaciones clonales (en manos de los agricultores o de bancos de germo- plasma) hayan acumulado mutaciones, muchas de ellas, favorables, las cuales, pueden ser aprovechadas.

Estas variaciones y la fuerte interacción que tiene esta especie con el ambiente (por su reñida relación con el termo-fotoperíodo) hacen que en el mundo se confundan ecotipos, biotipos, tipos comerciales y cultivares. Por otra parte, hay confusiones en las denominaciones populares, por lo que se requiere corregir esta situación.

Sólo para dar un ejemplo, al mismo tipo comercial de ajo en España se los llama "morados", en Argentina "colorados" y en Chile "rosados". Pero los "rosados" en Argentina son ajos subtropicales muy diferentes a los chilenos, y los "morados" de ese país son ajos asiáticos de bajos requerimientos de frío que nada tienen que ver con los "colorados" (Burba, 1997a).

El mejoramiento genético convencional tiene como objetivos:

- El aumento del rendimiento comercial.

- La ampliación del periodo de oferta (ya sea a través de la precocidad de los materiales o la prolongación de la vida útil pos cosecha).

- La concentración de principios organoazufrados (para mejorar las propiedades nutracéuticas o las aptitudes industriales).

- El mejor maridaje con las preparaciones culinarias.

La estrategia de mejoramiento genético del ajo en Argentina (segundo exportador mundial) apunta a la obtención de un producto diferenciado, con sólidas bases científicas y tecnológicas en los parámetros de diferenciación, estudiando y aprovechando la aún amplia variabilidad natural existente. 


\section{MÉTODOS CONVENCIONALES DE MEJORAMIENTO}

El sistema reproductivo de una especie condiciona la aplicación de los métodos tradicionales de mejoramiento, ya que aquel determina la variabilidad genética original; las posibilidades de generarla; el manejo durante el proceso de selección y la estructura genética de los posibles tipos de cultivares.

En muchos de los clones de ajo las flores son total o parcialmente sustituidas por bulbillos, no alcanzando por tanto a formar semillas; en otros no hay ni siquiera formación de escapo floral. Esta menor variabilidad natural y la imposibilidad de generarla por cruzamientos artificiales hacen que el ajo sea una de las especies cultivadas con mayores limitantes en la aplicación de los métodos convencionales de mejoramiento. Las posibilidades se reducen a la aplicación de selecciones sobre los materiales existentes y por tanto el éxito dependerá más que nunca de la variabilidad genética que se encuentre en las colecciones de trabajo. De ahí la importancia de apoyar la formación de bancos de germoplasma. Complementariamente a estas ideas, es conveniente señalar que la variabilidad somaclonal constituye, en esta especie, una interesante estrategia para la generación de variabilidad genética seleccionable (López Frasca et al., 1997).

Se comprobó que plantas de ajo regeneradas a partir del cultivo in vitro de tejidos (callos) mostraron marcada variabilidad para características fenotípicas como altura de planta, número de hojas, peso y forma de los "dientes" (bulbillos), características morfológicas de las "cabezas" (bulbos), coloración de hojas envolventes y presencia de bulbillos aéreos, a partir de las cuales fue posible la selección de somaclones sobresalientes que posibilitaron la creación de nuevos cultivares.

Para evaluar las posibilidades de aprovechar la variación fenotípica existente en una población clo- nal es necesario determinar cuánto de ella es de origen genético y cuánto ambiental. Los parámetros genéticos que expresan esta relación son dos:

- Heredabilidad en sentido amplio (h2) o grado de determinación genética:

$$
\begin{gathered}
\mathrm{h} 2=\mathrm{VG} /(\mathrm{VG}+\mathrm{VE}) \\
\mathrm{VG}=\text { variancia genética } \\
\mathrm{VE}=\text { variancia ambiental }
\end{gathered}
$$

- Coeficiente de variación genética (CVG):

$$
\begin{gathered}
(\mathrm{CVG}) \%=(\sqrt{ } \mathrm{VG} \sqrt{ } \mathrm{X}) * 100 \\
\mathrm{X}=\text { media }
\end{gathered}
$$

Además, resulta útil reunir información acerca de los grados de asociación de los distintos caracteres, lo que se estima a través de correlaciones fenotípicas $(\mathrm{rP})$ y genotípicas $(\mathrm{rG})$. Diversos autores han estimado la variabilidad genética de caracteres de interés comercial, sus correlaciones y su contribución como componentes del rendimiento (López Frasca et al., 1997).

En general, los resultados son coincidentes en estimar mayor heredabilidad en peso de bulbo, peso de bulbillos, número de bulbillos y altura de planta. En cuanto a las correlaciones genéticas, se encontraron valores altos y positivos entre diámetro y peso de bulbo, mientras que la contribución directa de diámetro y peso de bulbillos al rendimiento tuvo una respuesta variable de acuerdo con el ciclo de evaluación.

En Argentina, en colecciones de ajo tipo "rosado" (GE II), cultivado en la provincia mediterránea de Córdoba (centro del país), y en colecciones de los tipos "blanco" (GE III) y "colorado" (GE IVa), cultivados en la provincia de Mendoza (oeste del país), se encontró una apreciable variación genética, lo que confirma que estos tipos por su origen y estructura deben ser consideradas como poblaciones o "variedades criollas". 
En el ajo tipo "rosado", la heredabilidad en peso, perímetro y número de bulbillos por bulbo, al igual que número de hojas fértiles, indicó efectos ambientales preponderantes, aunque la mayor variabilidad aprovechable por selección (variabilidad genética) fue estimada en número y peso de bulbillos. También se determinó que el número y peso promedio de bulbillos por bulbo tuvieron efectos directos sobre el rendimiento y fueron los componentes de principal importancia.

Los resultados en ajo tipo clonal "blanco" confirmaron mayores posibilidad de selección en el carácter, peso y número de bulbillos y escasa variabilidad en número de hojas fértiles, en consecuencia poca oportunidad de selección. Considerando el alto grado de asociación a nivel fenotípico y genotípico que se presentó entre peso y diámetro y los valores heredabilidad, se previó un mayor avance en la selección de diámetro a través de la selección indirecta por peso.

La existencia de variación genética para número de bulbillos se confirmó por la respuesta a la selección, que les permitió obtener clones con distribuciones muy diferentes. En ensayos entre clones experimentales de ajo "colorado" se verificó una mayor variación en peso y una alta, positiva y significativa $(P \leq 0,01)$ correlación fenotípica entre diámetro y peso, que osciló entre 0,939 y 0,715 (López Frasca et al., 1997).

La metodología clásica de selección clonal puede ser masal o individual. La selección masal (que la puede realizar cualquier agricultor esmerado) es más efectiva desde el punto de vista de los volúmenes de "semilla" alcanzados, pero más lenta para encontrar las mejores respuestas (Burba, 1997b).

Se seleccionan importantes cantidades de bulbos "ideales" (buena forma, sanidad y compacidad), se calibran y eliminan los de diámetro más pequeño (los menores de 45 o $50 \mathrm{~mm}$ ). Los bulbos se desgranan, los dientes se clasifican y se plantan solamente los de mayor peso (por ejemplo, mayor a 2 gramos). Durante el cultivo se pueden eliminar plantas fuera de tipo y a partir de la cosecha se vuelven a repetir los pasos descritos. De esta manera, en 4 ó 5 años se puede contar con muy buen material, bastante homogéneo y adaptado a las condiciones locales.

La selección individual (que por lo general la realizan los organismos oficiales) alcanza más rápido los objetivos propuestos, pero es más lenta para obtener grandes cantidades de "semillas" disponibles.

A partir de una población local se estudia la frecuencia de caracteres deseables (formas, colores, calibres, número de dientes, etc.) y se define el ideotipo. Se eligen todos aquellos bulbos que respondan al ideotipo y cada bulbo constituye una familia. Los dientes de cada bulbo se plantan en una parcela individual. El número de familias no debería ser inferior a cien.

Durante el cultivo se analiza el comportamiento de cada familia y se eliminan todas aquellas que muestran anormalidades indeseables (síntoma de virosis, plantas dobles, etc.). Luego de la cosecha se analiza para cada familia el rendimiento (diámetro, peso y PER: peso específico relativo), y con una presión de selección aproximada al $50 \%$ se eliminan todas aquellas familias con mal o regular comportamiento (Burba, J.L., 1997b).

Repitiendo este proceso, en el transcurso de 6 ó 7 años puede lograrse una nueva variedad de ajo, capaz de superar en ensayos comparativos a los testigos locales. Este nuevo material, luego de inscribirse formalmente en un registro, pasa a la etapa de producción de "semilla".

\section{PRODUCCIÓN DE SEMILLA}

Para formalizar un programa de producción de "semilla" de ajo, debe contarse con legislación y normas específicas que protejan el patrimonio genético y sanitario de un país (Burba, 1990). 
Como se mencionó,, el ajo carece en la práctica de semilla verdadera, y por tanto se utilizan los "dientes" de los bulbos como órgano de multiplicación. Estos "dientes" acarrean por lo general serios problemas de plagas (nemátodos y eriófidos) y enfermedades (hongos, fitoplasmas y virus) éstas por tanto se transmiten de generación a generación, lo que obliga a organizar un sistema especializado de producción de "semilla".

Para el común de la gente, existen varios "tipos" de "semillas", sin embargo no siempre son claras las diferencias entre ellas. Hay una gran confusión en las denominaciones debido a lo complejo del sistema de producción. Es importante entonces conocer realmente qué alcance y utilidad tiene cada una de ellas y su denominación correcta (Burba, 1993).

Se utilizan, entre otros, los siguientes términos aplicados a la "semilla", los que no siempre están bien utilizados:

- Común o identificada.

- Fiscalizada (básica, registrada o certificada).

- Saneada o libre de virus.

- Original.

Existe una fuerte tendencia por parte del productor o empacador a utilizar (o vender) los descartes del ajo de consumo como "semilla", sin embargo las diferencias entre ambos productos son grandes: el punto de cosecha, la pureza genética, la sanidad, el tamaño de los "dientes" y la temperatura de conservación, sólo para mencionar algunas.

El ajo de consumo podría transformarse en "semilla común" si es sometido a ciertos análisis de laboratorio y estos arrojan resultados favorables. Por tanto, su propietario, bajo su más absoluta responsabilidad, podrá utilizarla o comercializarla como "semilla identificada". Por lo general, y aunque los resultados de los análisis sanitarios sean aceptables, estas "semillas" tienen escasa pureza genética.

La "semilla fiscalizada" es la que controla el estado a través de los organismos especializados, la cual tiene distintas categorías según su nivel de pureza y calidad: básica, registrada y certificada. Por lo general, solamente esta última es utilizada por los productores de ajo para consumo, mientras que las categorías anteriores son utilizadas por los "semilleros". Las básicas y registradas son las denominadas "semillas saneadas" o "semillas libres de virus", aunque estos términos merecen mayor explicación.

Las categorías básicas y registradas provienen de un proceso de laboratorio, en el cual se eliminan total o parcialmente los virus que posee. Es exagerado hablar de "semillas libres de virus" ya que es muy difícil asegurar que no contienen ninguna partícula de viral, por eso suelen llamarse "semillas saneadas" o "semillas de sanidad controlada".

Las "semillas saneadas" en los laboratorios se re contaminan en el campo en las sucesivas multiplicaciones, y con el paso del tiempo vuelven a adquirir los virus (transmitidos por pulgones y eriófidos), aunque en proporciones menores que las "semillas" crónicamente enfermas que nunca pasaron por este proceso. Por esta razón, sólo se controla de virus a las básicas y registradas y no a las certificadas.

Por lo anterior, se considera que existen en el mercado dos tipos de "semillas" certificadas:

- Aquellas que provienen de un sistema de saneamiento de virus (aunque ya estén parcialmente contaminadas).

- Las que no provienen de un sistema de saneamiento, aunque sí de selección y control de otro tipo de problemas (como nemátodos, eriófidos y algunos hongos). 
Las primeras siempre tienen un mayor potencial de rendimiento. La semilla (saneada o no) puede ser de variedades "impuras" (llamadas poblaciones clonales), es decir, son mezclas de varios tipos aunque se parezcan mucho, o de variedades "puras" (llamadas mono o policlonales). Estas últimas provienen de un programa de selección genética. La "semilla madre" que se entrega a los "semilleros" para su multiplicación se denomina comúnmente "semilla original".

También se confunden los establecimientos "criaderos" de los establecimientos "semilleros". Los primeros son los que producen nuevas variedades a través de los programas de mejoramiento genético (y producen "semilla original"), mientras que los segundos son los responsables de multiplicar ésta.

Si bien existe un mercado potencial para la exportación de "semillas de ajo", esta situación es muy delicada debido a la gran especificidad de adaptación que tienen las variedades. Sólo países del hemisferio sur con condiciones similares podrán importar "semilla". La venta y posterior adaptación transhemisférica, si bien no es imposible, es un negocio de mediano a largo plazo.

Las condiciones de los valles aislados y frescos tienen las mejores posibilidades de producir "semilla" de alta calidad. Si bien es deseable que existan zonas especializadas en la producción de semillas de ajo (un poco más frías que las zonas de producción de ajo para consumo), suele ser difícil su organización y protección del sistema semillero.

Cuando la situación anterior no es posible, se aconseja que cada productor o grupo de productores destinen un área especial de aproximadamente el $15 \%$ de lo que cultiva con ajos para consumo y produzca su propia semilla de tercera o cuarta multiplicación a partir de semilla básica adquirida en los establecimientos especializados.
Por ejemplo, si un productor cultiva cinco hectáreas para consumo necesitará destinar unos $6.000 \mathrm{~m}^{2}$ para producir su semilla de tercera multiplicación, unos $800 \mathrm{~m}^{2}$ para su semilla de segunda multiplicación, y $100 \mathrm{~m}^{2}$ para su semilla de primera, por lo que se verá obligado a adquirir una pequeña cantidad de semilla básica.

Partiendo de la premisa que la "semilla" es la principal responsable de los altos rendimientos comerciales, un programa "semillero" será obligatorio para cualquier zona productora. Ella sola explica más del $70 \%$ del rendimiento potencial a alcanzar.

\section{MANEJO DE SEMILLA BÁSICA}

Con el avance de la tecnología de producción de semilla de ajo, ya nadie duda sobre la importancia de la calidad de la misma, principal componente de los rendimientos comerciales del cultivo. El atributo calidad en semilla de ajo implica dos conceptos: calidad genética, es decir, alta pureza varietal, y calidad sanitaria, es decir, libre de patógenos sistémicos (Burba, 1990; Moriconi et al., 1991).

La semilla de alta pureza varietal (cultivares inscriptos por criaderos y producidos por semilleros inscritos) garantiza fundamentalmente un gran potencial de rendimiento comercial y gran uniformidad, no sólo en las características agronómicas (periodo de dormición, simultaneidad de emisión de vara floral, homogeneidad de punto de cosecha, etc.), sino características comerciales (grandes calibres, formatos uniformes, compacidad, etc.).

La semilla de alta sanidad (producida por laboratorios y viveros prestigiosos) garantiza estar libre tanto de patógenos como el causante de la "podredumbre blanca" (Sclerotium cepivorum y Sclerotium rolfsii), o de la "tristeza" (fitoplasma), 
como de nematodos (Ditylenchus dipsaci), o saneados de virosis de alta peligrosidad (OYDV, LYSV, entre otros).

Esta semilla se obtiene en diferentes etapas (tabla 1), en las que, durante varios años, participan criaderos, laboratorios, viveros y multiplicadores (Burba, 2009).

La semilla básica puede salir del laboratorio en forma de micro plantas o microbulbillos (obtenidos in vitro), o minibulbillos rusticados, los que deben continuar las sucesivas etapas de multiplicación en jaulas con mallas a pruebas de pulgones (jaulas antiáfidos), ya que son estos insectos los vectores de los principales virus.

Los propágulos (micro plantas, micro o minibulbillos) provenientes del laboratorio deben cultivarse en condiciones agroclimáticas similares a las requeridas por la variedad (cultivar), es decir, capaces de cumplir con los requerimientos termo y fotoperiódicos de ésta, pero en ambientes aislados como son las jaulas antiáfidos de alta seguridad.Una vez cumplida la primera multiplicación en jaulas fijas antiáfidos, es conveniente, desde el punto de vista económico, realizar la o las etapas siguientes en estructuras más económicas, instaladas directamente en suelo agrícola, denominadas túneles antiáfidos.
Los bulbillos aéreos de ciertas variedades (morados, colorados o castaños) pueden multiplicarse en canteros en forma de almácigos (microtúneles antiáfidos), bajo cobertura de una malla antiáfidos o manta térmica.

\section{POSIBILIDADES DE ADAPTACIÓN}

Se entiende por adaptación la capacidad que tienen los organismos para modificar su comportamiento ante una nueva situación y se acepta que ellos tienen mecanismos capaces de lograrlo (Burba, 1997a).

El ajo, originario de zonas con inviernos rigurosos y fotoperiodo primaveral largo (alrededor de $40^{\circ} \mathrm{N}$ ), se ha dispersado adaptándose hasta en las regiones tropicales, sin embargo el "precio" de esta adaptación se evidencia por la modificación de la pungencia, conservación poscosecha y calidad estética (gran número de dientes asociado a deformaciones o escaso número de dientes asociado a bajos rendimientos). Actualmente existe tecnología suficientemente probada para contribuir a que este proceso de adaptación tenga éxito en el corto o mediano plazo. El esquema agroecologista (más conservador y tradicional) consiste en introducir materiales, estudiar el manejo agronómico y efectuar selección clonal

Tabla 1. Categorías y subcategorías de ajo semilla de la clase fiscalizada.

\begin{tabular}{|c|c|c|c|}
\hline Ámbito de uso & Categoría & Subcategoría & Denominación \\
\hline \multirow{7}{*}{$\begin{array}{l}\text { Criaderos } \\
\text { Viveros o semilleros }\end{array}$} & \multirow{4}{*}{ Básica } & Pre inicial & MO \\
\hline & & Inicial & M1 \\
\hline & & Prefundación & M2 \\
\hline & & Fundación & M3 \\
\hline & \multirow{3}{*}{ Registrada } & Registrada 1 & M4 \\
\hline & & Registrada 2 & M5 \\
\hline & & Registrada 3 & M6 \\
\hline Productores de ajo de consumo & Certificada & Certificada & M7 en adelante \\
\hline
\end{tabular}

Fuente: Burba et al., 2009. 
para lograr nuevos ecotipos. Éstos, alcanzados en el mediano a largo plazo, podrán obtener altos rendimientos, aunque no aseguren siempre alta rentabilidad.

El esquema productivista (más audaz) posee las mismas dos etapas anteriores, pero reemplaza a la tercera por la utilización de tecnología más o menos sofisticada que modifique el comportamiento del cultivo en alguna de sus etapas. Los resultados, logrados en el corto o mediano plazo, quizás sacrifiquen rendimiento en campo, pero ofrecen la posibilidad de mejorar la rentabilidad por la oportunidad de la oferta. La pérdida de rendimiento está generalmente asociada con una mayor precocidad. Ambos esquemas combinados podrán ser herramientas valiosas para resolver los problemas de adaptación en una región determinada.

\section{Estrategias de adaptación}

En este proceso se utilizan dos vías: manejo del genotipo y manejo fisiológico. El conocimiento profundo de ambos aspectos facilitará las acciones.

\section{Poblaciones clonales, variedades y cultivares}

Prácticamente todos los cultivos de ajo del mundo están realizados con base en poblaciones clonales, producto de mezclas mecánicas y ausencia de programas de mejoramiento genético. El término poblaciones clonales encuentra resistencia para su adopción, sin embargo refleja mejor la realidad. Denominaciones como "biotipos", "ecotipos", "variedades", "genotipos", "tipos clonales", "tipos comerciales" sólo confunden la interpretación de resultados.

Gran parte de la bibliografía existente, con resultados aparentemente erráticos, es el producto de haber utilizado poblaciones clonales no descritas o poco conocidas. Las verdaderas "variedades cultivadas" o cultivares (genotipos), producto de planes sistemáticos de mejoramiento genético, podrán ser mono o policlonales, dependiendo de si se utilizó como modalidad la selección individual, la selección masal, o ambas. El conocimiento de los requerimientos ecofisiológicos de éstos permitirá tomar decisiones sobre las oportunidades de adaptación de dichos cultivares (Burba, 1997a).

\section{Relación genotipo x ambiente}

En una especie tan sensible como el ajo al termo y fotoperiodo (en ese orden), cuyo periodo de cultivo (C) y el de dormición (D) son fuertemente influenciados por el ambiente, debe (al menos teóricamente) cumplirse la ecuación:

$$
\mathrm{C}+\mathrm{D}=\mathrm{K} \text {, donde } \mathrm{K}=365 \text { días }
$$

Cuando se introducen cultivares de otras regiones (en o fuera del hemisferio en que nos encontramos) y esta sumatoria no se cumple, podemos decir que los cultivares no se adaptan y por tanto requieren de la modificación de las condiciones de manejo. Si la sumatoria $\mathrm{C}+\mathrm{D}$ $<365$, como es el caso de cultivares subtropicales cuando son llevados a regiones más frías y de fotoperiodos primaverales más largos, resta un periodo del año (desde la cosecha hasta el momento óptimo de plantación), en el cual probablemente la "semilla" sufra deterioros y comprometa el rendimiento.

Si la sumatoria $\mathrm{C}+\mathrm{D}>365$, como es el caso de cultivares de mucho requerimiento de frío y fotoperiodo largo cuando se llevan a regiones subtropicales, le sobra una fracción de tiempo que obligaría a plantar siempre tarde y por tanto con menores rendimientos. La adecuación de la época de plantación y el manejo del periodo de dormición (mediante el almacenamiento de la "semilla" en una relación tiempo-temperatura ideal para cada caso) serán las posibles soluciones para la adaptación del cultivar introducido.

Por otra parte, y teniendo en cuenta que el requerimiento fotoperiódico puede verse modificado por la cantidad de frío inductor recibido, podemos adaptar cultivares provenientes de regiones más frías a regiones subtropicales de altura. Los 
índices latialtimétricos de adaptación pueden ayudar a tomar decisiones. Así, cultivares de buen comportamiento a $35^{\circ}$ de latitud a 700 msnm pueden tener un comportamiento similar a $20^{\circ}$ de latitud, pero a $2.500 \mathrm{msnm}$.

\section{Manejo del periodo de dormición como estrategia}

\section{Relación temperatura y tiempo de almacenaje}

Son numerosas las experiencias realizadas aplicando bajas temperaturas a la "semilla" en la búsqueda de diferentes respuestas. La mayoría de los resultados alcanzados demuestran que, mientras más bajas sean las temperaturas y más largos los tiempos de almacenaje, los bulbos producidos disminuyen su calidad comercial o su productividad total, sin embargo hay resultados favorables que podemos aprovechar en un sistema "semillero".

Las respuestas directas o indirectas que podemos encontrar con el uso de las denominadas "frigoplantas" seguramente están condicionadas por el genotipo, las condiciones de almacenamiento, el estado fisiológico del órgano que recibe frío y las condiciones de campo a que serán sometidas.

\section{Efectos sobre la dormición y brotación}

El balance entre promotores e inhibidores y las proporciones relativas entre ellos controlarían la entrada y salida de dormición, y el efecto del frío en preplantación serviría de "gatillo" para modificar este balance en favor de los promotores (auxinas, giberelinas, citocininas) y en contra de los inhibidores (ABA o compuestos relacionados). A este último proceso se lo denomina frigoinducción ("choque de frío", "golpe de frío" o "vernalización"). A la semilla tratada se la denomina frigoinducida y a las plantas logradas se las llama frigoplantas (Burba, 2009).

El ajo requiere para bulbificar o "encabezar" dos condiciones: tomar cierta cantidad de frío y cre- cer con días largos. Existen variedades que tienen escasos requerimientos de frío y longitud del día (como es el caso de los "rosados", GE II), y otras que tienen altos requerimientos, como es el caso de los ajos "colorados" (GE IVa). Mientras más frío toma, los requerimientos de largo del día son menores. El aporte de frío artificial a la "semilla" que lo recibe "a cuenta" del frío invernal.

La frigoinducción se utiliza con diversos objetivos:

- Lograr precocidad en la cosecha de las mismas variedades utilizadas en la región.

- Adaptar ajos de zonas frías a zonas tropicales.

- Escalonar la cosecha.

Este tratamiento preplantación con bajas temperaturas a la semilla de ajo es una práctica antigua, utilizada para aumentar la velocidad de emergencia y acortar el ciclo vegetativo de las plantas en búsqueda del objetivo comercial de lograr primicias, aunque esto siempre está asociado con la caída de rendimientos y la aparición de disturbios fisiológicos como el "rebrote".

La base teórica se estudió a fines de la década del cincuenta, sin embargo, pasaron más de 30 años para que se promoviera como alternativa práctica y más de 50 años para que fuese utilizada como técnica de rutina. A inicios de la primera década del siglo XXI, todavía se presenta como una tecnología de uso restringido, ya que a la enorme cantidad de factores agronómicos que interactúan se le agrega el mal manejo de las cámaras frigoríficas.

En muchas regiones productoras de ajo en el mundo se trata con frío la "semilla" (proceso denominado vulgarmente "vernalización"), simplemente para darle mayor precocidad a las variedades típicas de la zona. Esa precocidad casi siempre está acompañada por menores rendimientos y aumento de deformaciones. 
En regiones tropicales de Brasil, donde sólo es factible cultivar ajos de poca calidad (por lo general pequeños, de muchos "dientes" y de escasa conservación), se utiliza el almacenamiento frigorífico de la "semilla" de variedades de mayor calidad, provenientes de regiones más frías (bulbos medianos a grandes, pocos "dientes", pero más grandes y de buena conservación).

En algunas zonas de Australia, Egipto o Corea, se dispone de suficiente experiencia para brindarle a la "semilla" diferentes "dosis" de frío, que producen bulbificación en distintos momentos, y de esa manera permiten escalonar la cosecha, disponiendo de programas de computación que permiten aportar el frío "exacto" en función del clima de una determinada campaña agrícola.

En Argentina, los primeros antecedentes datan de mediados de la década del setenta en Córdoba sobre ajos del tipo "rosado", sin embargo es una práctica que no se difundió. Consistía en tratamientos entre $5^{\circ} \mathrm{C}$ durante 60 días, lo que permitía acortar el ciclo del cultivo de 210 días a 150 días.

Como ya quedó expresado, se debe distinguir al "choque" de frío (que por lo general es el tratamiento a temperaturas inferiores a los $10^{\circ} \mathrm{C}$ ) de las temperaturas de almacenamiento de "semillas", que ocurre entre $14^{\circ} \mathrm{C}$ y $18^{\circ} \mathrm{C}$. Estas últimas tienen ventajas como la mayor sanidad, el mejor estado de hidratación o la uniformidad de la brotación y generalmente no poseen desventajas.

Acortarle la vida al cultivo de ajo para obtener primicias mediante alguna técnica implica por lo general pérdidas de rendimiento, aunque el mejor precio del mercado en ese momento puede compensarla ampliamente. La frigoinducción permite al diente semilla "tomar frío a cuenta del invierno", sin embargo, y debido a las diferencias térmicas en dicha estación entre año y año, hace que muchas veces los resultados sean erráticos.
Por otra parte, frigoinducir y plantar temprano no arroja los mismos resultados que realizar el tratamiento y plantar tarde. Asimismo, no todas las variedades de ajo reaccionan ante el estímulo de la misma manera.

Mientras más frío toma "se hace menos exigente al largo del día" (los requerimientos de largo del día son menores) y bulbifica o "encabeza" antes. Esta es una razón para aportarle frío artificial a la "semilla", que lo recibe "a cuenta" del frío invernal.

La "semilla" almacenada en frío produce varios resultados, dependiendo de la temperatura, del tiempo de almacenamiento, de la variedad, del estado de dormición que tenga el brote, de la fecha de plantación, etc. Estos efectos no siempre son deseables y ese es el "precio" que se paga cuando se modifican artificialmente a las plantas.

Entre los efectos deseables se pueden mencionar la brotación rápida (ya que el frío en "semilla" rompe el estado de reposo), la formación prematura del bulbo (ya que haber recibido frío la hace menos dependiente del largo del día) y, como consecuencia de esto, la cosecha anticipada. Entre los indeseables se encuentran los bajos rendimientos y la manifestación de deformaciones ("rebrotes"), que comprometen seriamente la comercialización. Estos efectos negativos son tanto más graves cuanto más bajas sean las temperaturas de almacenamiento y más largo el período del mismo.

Existe para cada región una y sólo una combinación exitosa entre variedad, tiempo y temperatura de almacenamiento, momento en que se realiza el tratamiento y época de plantación (figura 1). A pesar de ello, las cambiantes condiciones meteorológicas entre año y año modifican también esta combinación. Por esta razón, sólo en algunas regiones y después de muchas pruebas se consigue la combinación perfecta. 


\section{Momento de almacenamiento}

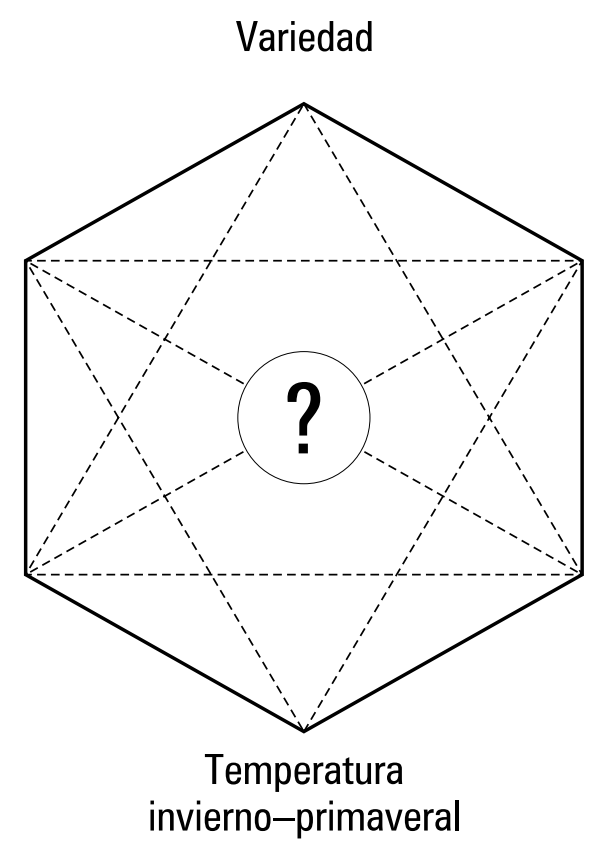

\section{Temperatura de} almacenamiento almacenamiento

Fuente: Burba, 2009.

Figura 1. Interrelaciones de los factores que afectan la producción de frigoplantas.

Como ya es conocido, los grandes grupos varietales de ajo tienen diferentes requerimientos de frío para bulbificar, por esta razón hoy existen variedades adaptadas a las diversas condiciones agroecológicas, desde regiones tropicales a nivel del mar hasta regiones frías a más 2.000 msnm. La tabla 2 muestra de manera sintética la relación entre los grandes grupos varietales y sus requerimientos de frío.

\section{LOS GRUPOS VARIETALES}

En el mundo moderno se reconocen ajos de todo tipo, sin embargo la selección natural que la especie ha sufrido, las denominaciones populares en las diferentes culturas, los intentos de los investigadores por agruparlos y los planes de mejoramiento genético han complicado el panorama y su interpretación. Los ajos pueden ser agrupados por sus características botánicas, fisiológicas o comerciales. Los intentos por hacerlo no fueron muy exitosos, complicándose aún más la situación debido a las barreras idiomáticas.

En la práctica comercial los ajos se denominan en algunos casos según el color de los bulbos, o el color de los "dientes" o bulbillos en otros. Este panorama es más complejo cuando de país en país las tonalidades reciben diferentes denominaciones. En español, los mismos tipos comerciales pueden denominarse rosa, rosado, rojo, violeta, morado o colorado. En portugués se denominan roxo y roxao. En italiano, rosso y rosa, y en francés, rose, rosé, rouge y violet.

Los grupos ecofisiológicos de Argentina, distinto para Francia, China o Japón, no serán motivo de este análisis, sin embargo, las mencionaremos, ya que dichas clasificaciones guardan fuerte relación con otros tipos de agrupamientos, generando muchas veces mayor confusión. 
Tabla 2. Relación entre cultivares y requerimientos de frío.

\begin{tabular}{|c|c|c|c|}
\hline Tipo comercial & Grupo ecofisiológico & Cultivares & Requerimientos de frío \\
\hline Rosados & $\|$ & Alpa Suquía & Muy bajos \\
\hline Morados & $\|$ & Morado INTA & Bajos \\
\hline Violetas & III & Lican INTA & Medios \\
\hline Blancos & III & $\begin{array}{l}\text { Norteño INTA } \\
\text { Nieve INTA } \\
\text { Unión } \\
\text { Perla INTA } \\
\text { Plata INTA }\end{array}$ & Medios \\
\hline Colorados & IV a & $\begin{array}{l}\text { Tempranillo } \\
\text { Gostoso INTA } \\
\text { Fuego INTA } \\
\text { Sureño INTA } \\
\text { Rubi INTA }\end{array}$ & Altos \\
\hline Castaños & $\mathrm{IV} \mathrm{b}$ & Castaño INTA & Muy altos \\
\hline
\end{tabular}

Fuente: Burba, 2009.

\section{Variedades botánicas}

A la especie Allium sativum L., denominada ajo común, ajo doméstico o ajo de huerta, se le conocen principalmente tres subespecies (botánicamente llamadas variedades), que son pekinense, sativum y ophioscorodon (tabla 3).

Según algunas escuelas populares, algunas de estas variedades estarían "especializadas" en producir bulbillos aéreos y otras en bulbillos subterráneos, aunque en rigor de verdad, según las condiciones ambientales de cultivo o las temperaturas del almacenamiento de la "semilla", las variedades pueden producir los dos tipos de propágulos, tal es el caso de ajos "blancos", que por lo general no emiten vara floral, pero sí lo hacen en regiones muy frías, y por consiguiente la denominación hardneck (de cuello duro o con vara floral) o softneck (de cuello blando o sin vara floral) es también relativa.

\section{Ajos de cuellos duros y de cuellos blandos}

En algunos ambientes de los Estados Unidos, a la var. sativum se la denomina popularmente como softneck, ya que interpretan que florece parcialmente o no lo hace, y por tanto presentan el "cuello blando fácil de trenzar" en el momento de la cosecha. Englobaría a todos aquellos ecotipos de abundante número de hojas fértiles y relativamente muchos "dientes".

Tabla 3. Equivalencia probable de las denominaciones vulgares de grupos varietales de ajo de "cuello duro" (hardneck).

\begin{tabular}{|l|l|l|}
\hline \multicolumn{2}{|c|}{ Sariedad botánica } & \multicolumn{2}{c|}{ Según England } \\
\hline pekinense & asiáticos (morados) & asiáticos \\
\hline ophioscorodon & rusos (castaños) & continental \\
\hline sativum & mediterráneos (colorados) & rocambole \\
\hline
\end{tabular}

Fuente: Burba, 2008. 
Denominan variedades de "cuello duro" (hardneck) a las que interpretan que siempre tienen tallo floral emergente y por tanto en el momento de la cosecha mantienen dicho cuello duro. Se consideran como var. sativum: los "violetas" (del tipo Violeta de Cadours o Germidour de Francia); los "blancos" (del tipo California Early de Estados Unidos), y también los "colorados", sean tanto ecotipos de "cuello duro" como de "cuello blando".

\section{Ajos rosados y morados}

Una misión científica china, radicada durante muchos años en la Estación Experimental de Caacupé (Paraguay), habría sido la responsable de la introducción de muchas variedades subtropicales (Fen Sang No. 1 y No. 2, entre otros). Éstos pertenecen al Grupo Ecofisiológico II de Argentina. Una población denominada "nacional" en Paraguay sería la misma denominada "rosado paraguayo" en Argentina.

Existen en Brasil numerosas poblaciones "asiáticas" o "subtropicales", como Amarante, Contestado y Lavinia; en Francia, estos grupos estarían representados por Rouge d'Afrique y Mallorí; en Japón, por Ishuwase y Okinawa, mientras en Italia, por Rosa di Napoli. Estos muestran plantas muy vigorosas, de cosecha temprana, bulbos grandes con muchos dientes pigmentados con estrías moradas, globoso piriforme, vara floral no emergente (queda incluida en el falso tallo pero puede presentar algunos bulbillos laterales grandes sobre el escapo), de poca conservación.

En Argentina, de la población denominada "paraguayo", se seleccionó Alpa Suquía y, probablemente, la variedad Rubí 1 de Colombia derive también de aquellas.

Los "ajos morados", mal llamados "ajos chinos", ya que en rigor son muchos y variados los procedentes de ese país, son poblaciones de plantas muy vigorosas, de cosecha temprana, bulbos grandes, pigmentados con estrías moradas, globosos achatados, de escasa conservación, poco ajustados en el cuello y "dientes" de color castaño claro.
En Argentina, los ajos "asiáticos" o "morados" (como la cultivar Morado INTA, similar a Xi'an de China), y los "rosados" (del tipo "rosado paraguayo") pertenecerían a la variedad botánica pekinense, aunque no hay coincidencia entre los autores. En Francia, Blanc d'Egypte (del que se seleccionó Ramsès), y un grupo de asiáticos precoces (de los que seleccionó Sprint), junto con los conocidos en Estados Unidos como Beijing, Sahntung Purple o Asian Tempest, pertenecerían también a esta variedad botánica.

\section{Ajos blancos y violetas}

Son ajos medianos a grandes, chatos, de color externo blanco o blanco amarillento, eventualmente con tintes violáceos, mediana cantidad de "dientes" (entre 8 y 14), de color lechoso o con leves tintes rosados o parduscos, distribuidos en varias hojas fértiles (entre tres y cinco), de cosecha temprana o semitemprana y en general de buena capacidad de conservación.

En Estados Unidos distinguen tres subtipos: artichoke, silverskin e italian. Los del subtipo artichoke presentan bulbos que muestran las puntas de bulbillos abiertos en la parte superior, similar a un alcaucil, del que provendría su nombre. La aparición de síntomas moderados de "rebrote", prolongando las hojas envolventes adicionales de los "dientes", le da un aspecto que también podría asemejarse a las brácteas del alcaucil.

En Argentina se pueden distinguir variantes como "blancos nativos", "blancos americanos" y "violetas". Son características de los "blancos nativos" las cultivares argentinas Blanco Mendoza, Nieve INTA, Norteño INTA, Plata INTA y Unión y las variedades francesas derivados de Blanc de la Drome (Messidrome y Thermidrome); los seleccionados de Blanc de Beaumont o de Lomagne (Jolimont y Corail) y los derivadas de Blanco de Ronda (Novatop) o Aguilar de la Frontera.

Entre los "blancos americanos" son típicas las cultivares California Early y Vigor Supreme (Es- 
tados Unidos), Perla INTA (Argentina), y entre los "violetas" Germidour (Francia) y Lican INTA (Argentina).

Los del subtipo silverskin presentan bulbos medianos, globosos piriformes, de color blanco níveo (o "plateados"), con muchas hojas fértiles (5 a 8), con numerosos "dientes" (18 a 24), de color blanco con tintes rosados, de cosecha muy tardía y largo periodo de conservación.

Los típicos representantes de este subtipo serían California Late de Estados Unidos y las francesas Rosé du Var (de la que se seleccionaron Jardinor, Cristo, Moulinen y Moulinor); Rose d'Auvergne (de la que se seleccionó Perle de Auvergne); Ail du Nord, d'Arleux, d'Arrase (de las que se seleccionaron Gayant, Artop y Atenor); Rose d'Italie (de la que seleccionó Rovigo 24); Rose de Brignoles (de la que seleccionó Brignoles 14); Rose de Corse (de la que se seleccionaron Fructidor y Printanor). También pertenecerían a este grupo Bianco Piacentino de Italia y Blanco de Chinchon de España.

\section{Ajos colorados y castaños}

Son ajos medianos a chicos, globosos a globosos achatados, de color externo blanco o blanco amarillento, eventualmente con tintes violáceos, con pocos "dientes" (entre 5 y 14), de colores rosados, violáceos o parduscos, distribuidos sólo en dos hojas fértiles, de cosecha semitardía o tardía y en general de muy buena capacidad de conservación.

En Estados Unidos, la variedad ophioscorodon es denominada popularmente ophios, topsetting (con bulbillos aéreos) y serpent garlic (por la forma retorcida del tallo floral). Serían materiales del tipo hardneck, debido a que interpretan que siempre tiene tallo floral emergente y por tanto en el momento de la cosecha mantienen el "cuello duro".

El subtipo rocambole se corresponde con los conocidos mundialmente como red garlic o purple garlic en Estados Unidos, ajos rojos o morados en
España, rosados en Chile o colorados en Argentina. Pertenecen al Grupo fisiológico I de Francia, Grupo IV de Argentina, Grupo 1 de Japón o Grupo 2B de China, con bulbos con envolturas blancas y "dientes" pigmentados entre rosa claro y morado oscuro.

La variedad denominada popularmente ophios, del subtipo rocambole, se trataría en realidad de ajos de "cuello duro", pero de la var. sativum y no de la variedad ophioscorodon, que, como se manifestó, se trataría de los tradicionales ajos rojos, y que Argentina posee inscritas varias cultivares como Colorado Mendoza, Fuego INTA, Gostoso INTA, Rubí INTA y Sureño INTA. Pertenecerían también a este subtipo Spanish Roja de Estados Unidos, algunas poblaciones francesas como Rose de Lautrec (de la que se seleccionaron Iberose y Goulurose; Violet de Kabyle (de la que se seleccionó Morasur); Rose d'Espagne (de la que se seleccionaron Morasol, Moraluz y Moratop); Cazador y Chonan (Brasil); Yamagata (Japón), Rosso di Sulmona (Italia), de la que seleccionó en Francia Sultop y Rosado Platina (Chile).

Estudios realizados sobre el comportamiento del Grupo fisiológico IV de Argentina, respecto a sus hábitos de floración, indican la existencia de subgrupos como "rusos", "mediterráneos" ("criollos" y "españoles") y "asiáticos", que en principio corresponderían respectivamente a los denominados Continental, Rocambole y asiáticos de la clasificación de Engeland.

Existen también diferencias de apreciación, ya que, para este autor, estos grupos tienen escasa conservación, mientras que para las condiciones locales los ajos "colorados" se consideran como ajos "nobles" por su presentación y "de guarda" por su capacidad de almacenamiento en el tiempo. Por otra parte, el término Rocambole (debido probablemente a la forma curvada del tallo floral cuando crece) se aplicó muchas veces a otras especies del género Allium. Rocambole o de España (ajo murciano o español), a veces denominada "cebolla de Egipto", es Allium scordoprasum L. 
Los ajos "colorados criollos" se caracterizan por poseer mayores requerimientos de frío y fotoperiodo largo en primavera; son de bulbos medianos a grandes, globosos achatados, con disco plano o levemente hundido y emisión relativamente temprana de vara floral. Mientras, por su parte, los "colorados españoles" poseen menores requerimientos de frío y fotoperiodo largo en primavera; son de bulbos medianos a chicos, globosos piriformes, con disco cóncavo y emisión tardía de vara floral.

El subtipo continental está considerado como el más próximo a los ajos silvestres nativos del antiguo Turkestán (Turkmenistán, Kirguizistán Kazajstán, Tajikistán y Uzbekistán). En Argentina son denominados popularmente como "ajos rusos", introducidos y cultivados en regiones muy frías y de los que se conoce sólo una cultivar monoclonal inscrita en los registros oficiales, denominada Castaño INTA.

Los "ajos rusos" tienen aroma y sabor muy similar a los ajos silvestres, y quienes son entendidos en apreciar flavors manifiestan que nadie conoce el verdadero sabor del ajo hasta no probar o degustar los ophios. Para los gourmets, el hecho que posean pocos "dientes" grandes y pesados, de sabor semisalvaje (intermedio entre crudo y cocido, pungente pero de aroma muy suave), y de fácil remoción del bulbo lo convierten en un ajo de gran perfomance culinaria.

Estas variedades se caracterizan por presentar plantas de hojas verde claro, de largos entre- nudos en el falso tallo y posición opuesta muy marcada, asemejando una hoja de palmera. El tallo floral es emergente, grueso y fuertemente lignificado, rematando en una umbela con gran espata, llena de flores estériles y bulbillos aéreos. Para algunos autores, la vara floral de este sub tipo aparece más tardíamente que en los Rocambole y poseen muchos bulbillos aéreos, pero de tamaño pequeño, sin embargo se citan datos que se contradicen con aquellos.

Los bulbos agrupan pocos y grandes "dientes" asentados sobre dos hojas fértiles. Existirían entre los "ajos rusos" variantes denominadas "porcelana" (de 4 a 6 "dientes" y "púrpuras" (de 8 a 12 "dientes"), refiriéndose al color de envoltura del bulbo. El color de los "dientes" es de base marrón o castaña, aunque pueden mostrar tintes rojizos.

Si bien se les atribuye escasa conservación, en principio ésta se debe a una extrema sensibilidad al ataque de eriófidos (Aceria tulipae), principal responsable del manchado y deshidratación de la hoja reservante. Cuando este problema sanitario es controlado su conservación es excelente.

En síntesis, para la clasificación argentina de ajos de "cuello duro", los cultivares Fuego, Gostoso y Sureño pertenecerían a la var. sativum del tipo comercial "colorado", mientras que Morado sería del tipo "asiático". Por su parte, Castaño pertenecería a la var. ophioscorodon y al tipo comercial "ruso". La tabla 4 resume esta situación. 
Tabla 4. Interpretación sintética del agrupamiento de cultivares de ajos argentinos de la especie Allium sativum L.

\begin{tabular}{|c|c|c|c|}
\hline Variedad & Tipos comerciales & Grupo ecofisiológico & $\begin{array}{l}\text { Cultivar típico } \\
\text { En argentina }\left(^{*}\right.\end{array}$ \\
\hline \multirow{6}{*}{ sativum } & \multicolumn{3}{|c|}{ softneck } \\
\hline & "blancos" (artichoke) & III & Nieve INTA \\
\hline & "violetas" & III & Lican INTA \\
\hline & "plateados" (silverskin) & & \\
\hline & \multicolumn{3}{|c|}{ hardneck } \\
\hline & "colorados" (rocambole) & IV a & Fuego INTA \\
\hline \multirow{2}{*}{ pekinense (asiáticos) } & "morados" & $\|$ & Morado INTA \\
\hline & "rosados" & $\|$ & Alpa Suquía \\
\hline ophioscorodon & "castaños" (continental) & $\mathrm{IV} \mathrm{b}$ & Castaño INTA \\
\hline
\end{tabular}

$\left({ }^{*}\right)$ No se descartan otros

Fuente: Burba, 2008.

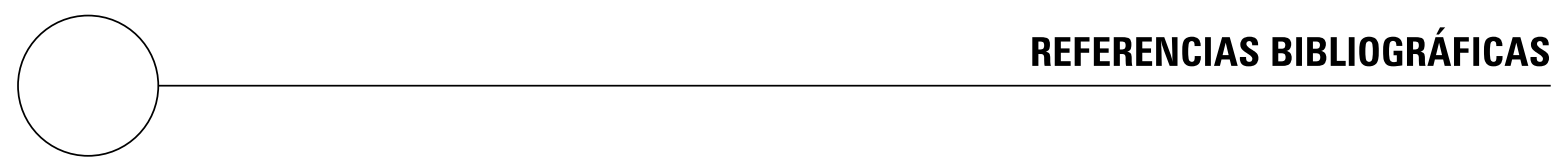

Burba, J.L. 1990. Producción de "semillas" de sanidad controlada en hortalizas de propagación agámica. pp. 245-250. En: Actas Curso-Taller en Tecnología de Producción de Semillas Hortícolas para Pequeños Agricultores. FAO-INTA, Mendoza, Argentina.

Burba, J.L. 1993. Producción de semilla de ajo. En: Crnko, J. (ed.). Manual de Producción de Semillas. INTA. Centro Regional Cuyo, Mendoza, Argentina. 1993. 136 p.

Burba, J.L. 1997a. Panorama mundial y nacional de poblaciones y cultivares de ajo. Posibilidades de adaptación. Cultivares y Producción de Semilla (INTA, Argentina) 2, 11-31.

Burba, J.L. 1997b. Obtención de nuevas cultivares de ajo. Cultivares y Producción de Semilla (INTA, Argentina) 2, 49-53.

Burba, J.L. 2008. Los grupos varietales del ajo (Allium sativum L.). Contribución para su entendimiento. Horticultura Argentina 27(62), 20-27.
Burba, J.L. 2009. Manejo de semilla de ajo frigoinducida. Documentos Proyecto Ajo/INTA 088. Estación Experimental Agropecuaria INTA La Consulta, Mendoza, Argentina.

Burba, J.L.; R. Ocañas; G.E. Lanzavecha y M. Paganini. 2009. Manejo de semilla básica de ajo en condiciones controladas. Documentos Proyecto Ajo/INTA 087. Estación Experimental Agropecuaria INTA La Consulta, Mendoza, Argentina.

López Frasca, A.; V. Silvestri y C. Rigoni. 1997. Métodos convencionales del mejoramiento genético del ajo. Cultivares y Producción de Semilla (INTA, Argentina) 2, 32-48.

Moriconi, D.N.; J.L: Burba y J. Izquierdo. 1991. Manual de intercambio y propagación de germoplasma de ajo a través de microbulbillos. FAO/RLAC-UN Córdoba, Santiago. 